\title{
Implementasi Pendidikan Karakter Masa Pandemi COVID-19 di Sekolah Dasar: Kajian Praksis
}

\author{
Sukarno, Sularmi, Suharno, Anesa Surya
}

Universitas Sebelas Maret

Sukarno57@staff.uns.ac.id

\section{Article History}

received 10/7/2021

\begin{abstract}
The success of character education during the COVID19 pandemic is an important key to shaping the personality of students. The purpose of this study was to identify the implementation of character education during the COVID-19 pandemic in elementary schools. The research method used in this study is a qualitative research method with the type of case study research. The research subjects included 15 elementary school teachers in Jogorogo District, Ngawi Regency. Data collection techniques are focus group discussions (FGD) and questionnaires. The technique of testing the validity of the data is using triangulation of techniques, sources and time. The data analysis technique used is Milles Huberman's interactive analysis technique which includes data collection, reduction, data presentation and conclusion drawing. The results of this study indicate that the implementation of character education during the COVID-19 pandemic requires synergy between the family, school and community environment. Thus, it is important that the learner's environment supports the development of character education in elementary schools.
\end{abstract}

Keywords: character education, COVID-19 pandemic, elementary school

\begin{abstract}
Abstrak
Keberhasilan pendidikan karakter dalam masa pandemi COVID19 merupakan kunci penting untuk membentuk kepribadian peserta didik. Tujuan penelitian ini adalah mengidentifkasi implementasi pendidikan karakter selama masa pandemi COVID-19 di sekolah dasar. Metode penelitian yang digunakan dalam penelitian ini adalah metode penelitian kualitatif dengan jenis penelitian studi kasus. Subjek penelitian meliputi 15 guru Sekolah Dasar Kecamatan Jogorogo, Kabupaten Ngawi. Teknik pengumpulan data adalah Focus Group Discussion (FGD) dan kuesioner. Teknik uji validitatas data adalah menggunakan triangulasi teknik, sumber dan waktu. Teknik analisis data yang digunakan teknik analis interaktif Milles Huberman yang meliputi pengumpulan data, reduksi, penyajian data dan penarikan kesimpulan. Hasil penelitian ini menunjukkan implementasi pendidikan karakter selama masa pandemi COVID-19 membutuhkan sinergitas antara lingkungan keluarga, sekolah dan masyarakat. Dengan demikian, penting lingkungan peserta didik mendukung pengembangan pendidikan karakter di sekolah dasar.
\end{abstract}

Kata kunci: pendidikan karakter, pandemi COVID 19, sekolah dasar 


\section{PENDAHULUAN}

Persiapan pendidikan untuk menghadapi persaingan abad 21 adalah menyediakan proses pembelajaran yang berbasis sumber daya alam menjadi pengetahuan dan keterampilan teknologi (Trilling \& Fadel, 2009). Pembelajaran abad 21 menuntut peserta didik untuk kreatif, inovatif, berfikir kritis dan metakognitif sehingga memiliki kemampuan berkomunikasi dan bekerja kolaborasi (Abdullah \& Osman, 2010). Harapannya, pengetahuan dan keterampilan yang diperoleh dapat dijadikan bekal hidup di masyarakat yang memiliki karakter baik lokal maupun global dan dapat dipertanggung jawabkan secara personal maupun sosial masyarakat.

Di balik dampak positif abad 21, teknologi jika tidak diimbangi oleh penanaman pendidikan karakter maka akan menimbulkan krisis nilai karakter (Prihatmojo, A. \& Badawi, 2020). Karakter dapat juga disebut watak, yaitu "paduan segala tabiat manusia yang bersifat tetap, sehingga menjadi ciri khusus yang membedakan orang satu dengan yang lain" (Sukadari, 2018). Nilai karakter adalah ukuran baik atau buruk yang diberikan pada watak atau kepribadian individu dalam kehidupan sehari-hari. "Nilai karakter merupakan jati diri yang melekat pada individu dengan menunjukkan nilai-nilai tertentu" (Manan, 2018). Sama halnya dengan karakter, nilai karakter menjadi pembeda antara satu individu dengan individu lainnya yang tercermin dalam prilaku atau sifat serta watak atau tabiat. Nilai karakter terdiri atas tiga hal yaitu: pengetahuan moral, perasaan moral dan prilaku moral. Pengetahuan Moral meliputi: Kesadaran moral, pengetahuan nilai moral, penentuan presfektif, pemikiran moral, pengambilan keputusan dan pengetahuan pribadi. Perasaan Moral meliputi: Hati nurani harga diri, empati, mencintai hal yang baik, kendali diri dan kerendahan hati. Tindakan Moral meliputi: kompetensi, keinginan dan kebiasaan (Lickona, 2018). Ketiga hal tersebut saling berhubungan satu sama lain serta saling mempengaruhi.

Semakin maju teknologi dapat menyebabkan memudarnya nilai karakter sehingga diperlukan fondasi pendidikan karakter. Pendidikan karakter diartikan sebagai pendidikan yang mengembangkan nilai-nilai budaya dan karakter bangsa pada diri peserta didik, sehingga mereka memiliki dan menerapkan nilai-nilai tersebut dalam kehidupan berbangsa dan bermasyarakat (Putro, Waluyo, \& Wardhani, 2020). Pendidikan karekater meliputi sebuah proses yang terus berkelanjutan, sehingga hasilnya berupa perbaikan agar terwujud manusia yang berakar pada nilai-nilai filosofis budaya bangsa dan mengamalkan karakter bangsa secara utuh (Muazimah \& Wahyudi, 2020). Penerapan pendidikan karakter di sekolah dapat dilakukan dengan mengintegrasi nilai karakter kedalam sejumlah aspek mata pelajaran (termasuk muatan lokal), kegiatan pembelajaran, budaya sekolah serta kegiatan ekstrakurikuler (Juadani, 2010; Sultono \& Hasan, 2020). Tujuan pendidikan karakter adalah dalam menghasilkan individu yang memiliki kecerdasan dan karakter yang mulia (Nuryanto, 2017). Tujuan pendidikan karakter pada dasarnya dalah membentuk perilaku peserta didik yang bermoral tinggi (Jeynes, 2019). Tujuan pendidikan karakter harus diterapkan sejak dini.

Prinsip-prinsip pendidikan karakter perlu diperhatikan guru untuk membentuk pengetahuan dan cara berperilaku peserta didik. Prinsip untuk mewujudkan pendidikan karakter yang efektif sebagai berikut: (1) Mempromosikan nilai-nilai dasar etika sebaga basis karakter; (2) Mengindetifikasi karakter secara komprehensi supaya mencakup pemikiran, perasaan, dan prilaku; (3) Menggunaka pendekatan yang tajam, proaktif dan efektif untuk membangu karakter; (4) Menciptakan komunitas sekolah yang memiliki kepedulian; (5) Memberikan kesempatan kepada peserta didik untuk menunjukka perilaku yang baik; (6) Memiliki cakupan terhadap kurikulum yan bermakna dan menantang yang menghargai semua peserta didik membangun karakter mereka, dan membantu mereka untuk sukses; (7 Mengusahakan tumbuhnya motivasi diri pada pada peserta didik; (8 Memfungsikan seluruh staf sekolah sebagai komunitas moral yan berbagi tanggungjawab untuk pendidikan karakter dan setia pada nila dasar yang sama; 
(9) Adanya pembagian kepemimpinan moral dan dukungan luas dalam membangun inisiatif pendidikan karakter; (10 Memfungsikan keluarga dan anggota masyarakat sebagai mitra dalam usaha membangun karakter; (11) Mengevaluasi karakter sekolah, fungsi staf sekolah sebagai guru-guru karakter, dan manifestasi karakter positif dalam kehidupan peserta didik (Kemendiknas, 2010).

Implementasi model pendidikan karakter yang selama ini diterapkan di Indonesia berupa pengintegrasian pendidikan karakter dalam pembiasaan, pembelajaran, dan kegiatan ekstrakurikuler (Sukadari, 2018). Sekolah diberikan keleluasaan untuk merancang kegiatan pembiasaan, pembelajaran, dan ekstrakurikuler dengan pengintegrasian karakter. Namun, selama pandemi COVID-19 dengan berlangsungnya pembelajaran daring, implementasi pendidikan karakter belum dapat berjalan secara efektif. Berdasarkan hasil survei yang dilakukan oleh Kemdikbud, kondisi pembelajaran daring yang diberikan oleh guru selama ini menitikberatkan pada aspek pengetahuan. Dengan total responden 174 guru menyatakan bahwa 59, 4 \% guru memberikan porsi materi pendidikan karakter/akhlak lebih sedikit dibandingkan dengan aspek pengetahuan (Kemendiknas, 2011). Selama ini, guru hanya memberikan tugas secara bertahap. Sedangkan untuk pemantauan sikap peserta didik menjadi kurang terkontrol. Hal ini mengindikasikan bahwa dalam pembelajaran daring di masa pandemi ini terjadi adanya degradasi moral. Degradasi atau kemerosotan moral adalah suatu fenomena terjadinya kemunduran akhlak atau budi perkerti seseorang maupun kelompok.

Penelitian Rosydah (2014) menunjukkan kepribadian peserta didik di sekolah dasar belum terbentuk seacara optimal. Penelitian Marini (2017) juga menunjukan bahwa pendidikan karekater melalui guru belum sepenuhnya diterapkan dengan baik. Dengan demikian di sekolah dasar perlu dilakukan pengembangan pendidikan karakter (Muttaqin, Raharjo \& Masturi, 2018) Hasil tersebut diperkuat berdasarkan hasil pra survei di SD Kecamatan Jogorogo Kabupaten Ngawi pada tanggal 12 Januari 2020 (forum KKG). Hasil pra survei menunjukkan fakta bahwa: 1) guru membuat RPP dengan mengintegrasikan karakater dalam pembelajaran daring namun belum mengidentifkasi kesesuaian dengan perbedaaan kebutuhan/karakteritika peserta didik, 2) guru dalam pelaksanaan pembelajaran menekankan pada aspek pengetahuan sehingga penanamkan karakter menjadi kabur, 3) guru menilai pembelajaran mengacu pada sikap yang dituliskan dalam RPP, 4) kegiatan pembiasaan tidak dilakukan, 5) kegiatan ekstrakurikuler tidak dikembangkan. Dengan demikian dapat disimpukan, implementasi pendidikan karakter selama pembelajaran daring sebagi akibat COVID-19 belum dapat menanamkan karakter yang kondusif bagi peserta didik sekolah dasar.

Berdasarkan urain di atas, penelitian ini akan mengidentifkasi implementasi pendidikan karakter di sekolah dasar. Tujuan penelitian ini meliputi 1) mendeksprisikan implementasi pendidikan karakter di sekolah dasar kabupaten Ngawi, 2) Mendeskripsikan hambatan mendeksprisikan implementasi pendidikan karakter di sekolah dasar kabupaten Ngawi, 3) Mendeskrpsikan solusi yang dilakukan dalam mengatasi hambatan implementasi implementasi pendidikan karakter di sekolah dasar kabupaten Ngawi.

\section{METODE}

Metode penelitian yang digunakan dalam penelitian ini adalah metode penelitian kualitatif dengan jenis penelitian studi kasus. Penelitian studi kasus adalah sebuah metode penelitian yang secara khusus menyelidiki fenomena kontemporeryang terdapat dalam konteks kehidupan nyata, dengan menggunakan berbagai sumber data (Sugiono, 2017). Lokasi penelitian adalah Sekolah Dasar Kabupaten Ngawi dengan sampel Sekolah Dasar Kecamatan Jogorogo. Waktu penelitian dilaksanakan selama 8 tahun. Sumber data yang digunakan dalam penelitian adalah guru Sekolah Dasar Kecamatan Jogorogo, Kabupaten Ngawi. 
Teknik pengumpulan data adalah focus group discusion (FGD), wawancara, dan angket. Tujuan melakukan FGD adalah memperoleh data tentang implementasi, hambatan dari pelaksanaan pendidikan karakter FGD berdasarkan informasi dari guru sekolah dasar. Tujuan melakukan wawancara adalah untuk croscheck data tentang tentang implementasi, hambatan dari pelaksanaan pendidikan karakter berdasarkan informasi dari guru. Tujuan teknik pengumpulan data melalui angket adalah mengetahui tentang implementasi, hambatan dari pelaksanaan pendidikan karakter berdasarkan informasi guru sekolah dasar. Dokumen yang dianalisis adalah rencana pelaksanaan pembelajaran, hasil catatan harian dan foto. Teknik uji validitas data adalah menggunakan triangulasi. Triangulasi yang digunakan adaah triangulasi teknik, sumber dan waktu. Teknik analisis data yang digunakan teknik analis interaktif Milles Huberman yang meliputi pengumpulan data, reduksi, penyajian data dan penarikan kesimpulan. Langkah dalam melaksanakan analisis data meliputi 1) data kuesioner dianalisis deskriptif, 2) membanding data kuesioner dengan data FDG, 3) memilih kesesuaian data kuesioner dan data FGD yang valid.

\section{HASIL DAN PEMBAHASAN}

Hasil peneliian dan pembahasan yang dilaksanakan dalam penelitian ini terdiri dari hasil mendeskripsikan implementasi pendidikan karakter saat masa pandemi COVID19 , mengidentifikasi hambatan implementasi pendidikan karakter saat masa pandemi COVID-19, dan mendeskripsikan solusi yang dilakukan dalam mengatasi hambatan implementasi pendidikan karakter. Untuk lebih jelaskan sebagai berikut:

\section{Mendeskripsikan implementasi pendidikan karakter saat masa pandemi COVID-19}

Kegiatan yang dilakukan dalam tahap ini adalah menggali informasi mengenai pemahaman guru tentang implementasi pendidikan karakter saat masa pandemi COVID-19 di sekolah dasar. Subjek penelitian yang digunakan adalah 15 guru sekolah dasar di Kecamatan Jogorogo dan Kabupaten Ngawi Teknik mengumpulkan data yang digunakan adalah kuesioner terbuka yang terdiri dari 10 pertanyaan. Berdasarkan hasil analisis terhadap kuesioner yang telah diisi maka dapat disimpulkan bahwa guru dalam menerapkan pendidikan karakter adalah dengan cara memberikan informasi tentang pendidikan karakter melalui video secara daring, membiasakan diri melakukan kegiatan dengan menerapkan pendidikan karakter melalui video dan memberikan teladan dalam pembentukan karakter anak melalui video secara daring. Hal ini sesuai dengan penelitian Anisa (2021) yang mengemukakan bahwa pengembangan video dalam pembelajaran daring yang terbukti efektif dapat digunakan sebagai pendidikan karakter.

\section{Mengidentifikasi hambatan implementasi pendidikan karakter saat masa pandemi COVID-19}

Berdasarkan hasil kuesioner maka dapat disimpulkan sebagai berikut:

a. Sebagain besar guru kesulitan dalam mengembangkan pendidikan karakter pada anak didik saat masa pandemi COVID-19.

b. Sebagian besar guru kesulitan untuk mensinergitaskan lingkungan keluarga, sekolah dan masyarakat untuk mendukung pendidikan karakter.

Hasil penelitian tersebut sesuai dengan penelitian Nitte \& Bulu (2020) yang menjelaskan bahwa hambatan dalam impelementasi pendidikan karakter selama pembelajaran dairng kurang optimal. Selain itu hambatan dalam mengimplementasikan pedidikan karakter khusunya karakter kejujuran pembelajaran daring kurang mendapatkan dukungan yang optimal oleh keluarga (Efendi, Barkar, Fitria, 2020).

\section{Mendeskripsikan solusi yang dilakukan dalam mengatasi hambatan implementasi pendidikan karakter}

Salah satu alternatif solusi yang dapat digunakan untuk mengatasi masalah terbut adalah dengan menggunakan kemitraan sekolah. Kemitraan sekolah memiliki tujuan untuk mewujudkan lingkungan pendidikan yang dapat menumbuhkan karakter, prestasi 
akademik, sosial dan emosional anak (Bern, 2011; Henderson, A. T., \& Mapp, 2002). Selain itu dalam mewujudkan Pendidikan dasar yang berkualitas perlu adanya kerjasama yang erat antara lingkungan keluarga, lingkungan sekolah dan lingkungan masyarakat agar terjadi harmonisasi terutama dalam masa pandemi COVID 19 (Saleh, 2020; Sukarman 2020)

Kemitraan sekolah yang dikembangkan mengacu pada pendekatan partisipatif. Istilah partisipasi merupakan terjemahan dari istilah yang diadopsi dari bahasa Inggris "participation. Menurut Kamus Bahasa Indonesia partisipasi diartikan sebagai "pengambilan bagian" atau "pengikutsertaan". Partisipasi adalah keikutsertaan, peran serta atau keterlibatan yang berkitan dengan keadaaan lahiriahnya (Sangian et al., 2013). Menurut konsep proses pendidikan, partisipasi merupakan bentuk tanggapan atau responses atas rangsangan-rangsangan yang diberikan; yang dalam hal ini, tanggapan merupakan fungsi dari manfaat (rewards) yang dapat diharapkan (Sumarsono, 2019).

Sedangkan inovasi yang dapat pendidik lakukan untuk mengimplementasikan pendidikan karakter dalam situasi COVID-19 yaitu pembelajaran daring dimulai dengan merencanakan pembelajaran yang menarik. Hal itu agar menimbulkan rasa ingin tahu peserta didik. Dalam pelaksanaannya, pendidik dapat mengimplementasikan kedisiplinan dengan menepati waktu pembelajaran daring ataupun saat pengumpulan tugas. Pendidik dapat menguraikan materi dan memberikan soal yang mengandung nilai demokratis, semangat kebangsaan, cinta tanah air, peduli sosial, peduli lingkungan, dan cinta damai. Mengembangkan nilai demokratis dapat diwujudkan dengan diberikan soalsoal open ended. Menumbuhkan semangat kebangsaan dan cinta tanah air dapat ditempuh dengan mengambil tema pembelajaran yang berkaitan dengan Indonesia. Sementara nilai peduli sosial dan lingkungan hidup dapat dicapai dengan membentuk kelompok diskusi yang harus peserta didik lakukan secara daring. Sehingga rasa cinta damai ada diri siswa dapat tegugah.

Nilai komunikatif dapat dibiasakan pendidik melalui tanya jawab setelah pemaparan materi. Nilai mandiri, kreatif, kerja keras, tanggungjawab, gemar membaca dan jujur dapat diimplementasi pendidik dengan memberikan latihan soal sehingga pendidik dapat melihat bagaimana tanggungjawab, gemar membaca materi yang diberikan, kemandirian, kejujuran juga kreatifitas peserta didik dalam menyelesaikan tugas yang diberikan (Fanya, 2020). Pendidik dapat menyelipkan nilai religius dan toleransi pada sela-sela pemaparan materi. Pendidik juga harus mengimplementasikan nilai menghargai prestasi peserta didik dengan memberikan reward berupa pujian atau bahkan barang jika ia mempunyai kelebihan dalam mengikuti pembelajaran daring yang telah berlangsung.

\section{SIMPULAN}

Berdasarkan uraian diatas maka dapat disimpulkan bahwa implementasi pendidkan karakter selama ini kurang optimal. Hambatan yang dialami adalah kurangnya sinergitas anatara lingkungan keluarga, sekolah dan masyarakat untuk mengimplementasikan pendidikan karakter secara berkesinambungan. Solusi yang dapat digunakan untuk mengatasi masalah tersebut adalah dengan mengembangkan kemitraan sekolah dengan pendekatan partisipatif dengan metode daring yang inovatif. Dengan demikan, penting bagi sekolah untuk merancang kemitraan sekolah berbasis pendekatan partisipatif yang inovatif.

\section{DAFTAR PUSTAKA}

Abdulloh, M. \& Osman, K. (2010). 21 st century inventive Thinking skills among primary students in Malaysia and Brunei. Procedia-Social Behavioral Science, 9(20),6461645 
Anisa, S. (2021). Pengembangan media video pembelajaran pendidikan karakter bertema budaya sipakatau' berbasis luring di SD Negeri 48. Journal of Educational Technology, Curriculum, Learning, and Communication, 1(2), 97-102.

Bern, R. M. (2011). Child, Family, Scholl, Community Socialization and Support. Australia: Thomson Learning.

Efendi, N., Barkara, R. S., Fitria, Y. (2020). Implementasi karakter peduli lingkungan di Sekolah Dasar Lolong Belanti Padang. Jurnal Komunikasi Pendidikan, 4(2), 1-10.

Fanny, A. M. (2020). Sinergitas Tripusat Pendidikan Dalam Program Penguatan Pendidikan Karakter (Ppk) Di SD Dalam Pandangan Ki Hajar Dewantara. Jurnal Pendidikan Dasar, IV(2), November 2020. Retrieved from https://journal.unesa.ac.id/index.php/jpd

Henderson, A. T., \& Mapp, K. L. (2002). A new wave of evidence: The impact of school, family and community connections on student achievement. Austin: TX: Southwest Educational Development Lab.

Jeynes, W. H. (2019). A meta-analysis on the relationship between character education and student achievement and behavioral outcomes. Education And Urban Society, 51(1), 33-71. Https://Doi.Org/10.1177/0013124517747681.

Juadani, S. (2010). Implementasi pendidikan karakter di sekolah dasar melalui penguatan kurikulum. Jurnal Pendidikan dan Kebudayaan, 16(3), 280-289.

Kemendikbud. 2011. Panduan pembinaan pendidikan karakter melalui pengembangan budaya sekolah di sekolah dasar. Jakarta: Dirjend Pendas.

Kemendiknas, (2010). Disain induk pendidikan karakter kementerian pendidikan nasional, Jakarta: Direktorat Mandikdasmen.

Lickona, T. 2012. Mendidik untuk membentuk karakter: bagaimana sekolah dapat memberikan pendidikan tentang sikap hormat dan bertanggung jawab. (Terj.: Wamaungo). Jakarta: PT. Bumi Aksara

Mahliana, L., \& Mustikarini, I. D. (2013). Pendidikan karakter anak melalui seni batik. Citizenship Jurnal Pancasila Dan Kewarganegaraan, 1(2), 119. Https://Doi.Org/10.25273/Citizenship.V1i2.1102

Manan, M. A. (2018). Internalisasi nilai-nilai karakter dalam meningkatkan kompetensi kepribadian guru di smp ibrahimy 1 sukorejo situbondo. Jurnal Pendidikan Islam Indonesia, 3(1), 18-31. Https://Doi.Org/10.35316/Jpii.V3i1.84.

Marini, Arita. (2017). Character building through teaching learning process: lesson in indonesia. PONTE International Scientific Researchs Journal, 73(5), 171-182.

Muazimah, A., \& Wahyuni, I. W. (2020). Pendidikan karakter berbasis kearifan lokal melalui permainan tradisional tarik upih dalam meningkatkan motorik kasar anak. Jurnal Pendidikan Islam Anak Usia Dini, 3(1), 70-76.

Muttaqin, M. F., Raharjo, T. J., \& Masturi. (2018) the implementation main values of character education reinforcement in elementary school. Journal of Primary Education, 103-112 https://doi.org/10.15294/jpe.v7i1

Nitte, Y., \& Bulu, V. (2020). Pemetaan Implementasi Pendidikan Karakter di Sekolah Dasar se- Kota Kupang. Jurnal Kependidikan: Jurnal Hasil Penelitian dan Kajian Kepustakaan di Bidang Pendidikan, Pengajaran dan Pembelajaran, 6(1). doi:https://doi.org/10.33394/jk.v6i1.2326

Nuryanto, S. (2017). Peningkatan nilai-nilai karakter dengan metode mendongeng cas cis cus Di Ba Aisyiyah Kaponan 2 Ponorogo. Journal Of Nonformal Education, 3(1), 1-20. Https://Doi.Org/10.24914/Pnf.V3i1.8732.

Presiden Republik Indonesia. (2017). Undang-undang No. 20 Tahun 2003 tentang Sistem Pendidikan Nasional pasal 3. "Pendidikan karakter.

Presiden Republik Indonesia. (2017). Peraturan Presiden (Perpres) Nomor 87 Tahun 2017 tentang Penguatan Pendidikan Karakter.

Prihatmojo, A. \& Badawi. (2020). Pendidikan karakter di sekolah dasar mencegah degradasi moral di era 4.0. DWIJA CENDEKIA: Jurnal Riset Pedagogik, 4(1) 
(2020)

142152.

Retrieved

from

https://jurnal.uns.ac.id/jdc/article/view/41129/28119

Putro, A. P., Waluyo, H. J., \& Wardhani, N. E. (2020). Nilai-nilai pendidikan karakter dalam naskah drama opera kecoa karya n. Riantiarno. Dialektika : Jurnal Bahasa, Sastra, Dan Pendidikan Bahasa Dan Sastra Indonesia, 7(1), 1-16. Https://Doi.Org/10.1155/2010/706872

Rusydiyah, E.F. (2014). Character education through the constructivist design of islamic education subject at elementary school pembangunan jaya ii in gedangan sidoarjo. Altalimjournal, 21(3), 221-238.

Saleh, R. S. (2020). Reinterpretasi Tri Pusat Pendidikan: Sebuah Telaah Kritis FilosifisPedagogis. Journal of Elementary Education, 3(2), 58-63.

Sangian, D. A., Dengo, S., \& Pombengi, j. D. (2013). Pendekatan partisipatif dalam pembangunan di desa tawaang kecamatan tenga kabupaten minahasa selatan. Journal of Chemical Information and Modeling, 53(9), 1689-1699.

Sugiyono. (2017). Metode penelitian kuantitatif, kualitatif, dan r\&d. Bandung : Alfabeta, CV.

Sukadari. (2018). Implementasi pendidikan karakter melalui budaya sekolah. Yogyakarta: Kanwa Publisher.

Sukarman. (2020). Sinergitas Peran Tri Pusat Pendidikan Dalam Pembelajaran Berbasis Daring Di Masa Pandemi COVID-19. MAGISTRA, 11 (2), 112-129.

Sultoni, Imam G. \& Hasan A. (2020). Dampak pembelajaran berkarakter terhadap penguatan karakter siswa generasi milenial. JAMP: Jurnal Adminitrasi dan

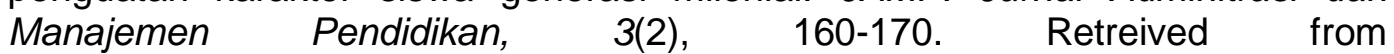
http://journal2.um.ac.id/index.php/jamp/

Sumarsono, R. B. (2019). Upaya Mewujudkan Mutu Pendidikan Melalui Partisipasi Orangtua Siswa. Jurnal IImu Pendidikan, 24(2), 63. https://doi.org/10.17977/um048v24i2p63-74

Trilling, B. \& Fadel, C. (2009). San Francisco: Jossey-Bass. 